\title{
Low autophagy capacity implicated in motor system vulnerability to mutant superoxide dismutase
}

\author{
Eiichi Tokuda ${ }^{1,3}$, Thomas Brännström¹, Peter M. Andersen² and Stefan L. Marklund ${ }^{1 *}$
}

\begin{abstract}
Introduction: The motor system is selectively vulnerable to mutations in the ubiquitously expressed aggregationprone enzyme superoxide dismutase-1 (SOD1).

Results: Autophagy clears aggregates, and factors involved in the process were analyzed in multiple areas of the CNS from human control subjects $(n=10)$ and amyotrophic lateral sclerosis (ALS) patients $(n=18)$ with or without SOD1 mutations. In control subjects, the key regulatory protein Beclin 1 and downstream factors were remarkably scarce in spinal motor areas. In ALS patients, there was evidence of moderate autophagy activation and also dysregulation. These changes were largest in SOD1 mutation carriers. To explore consequences of low autophagy capacity, effects of a heterozygous deletion of Beclin 1 were examined in ALS mouse models expressing mutant SOD1s. This caused earlier SOD1 aggregation, onset of symptoms, motor neuron loss, and a markedly shortened survival. In contrast, the levels of soluble misfolded SOD1 species were reduced.
\end{abstract}

Conclusions: The findings suggest that an inherent low autophagy capacity might cause the vulnerability of the motor system, and that SOD1 aggregation plays a crucial role in the pathogenesis.

Keywords: Amyotrophic lateral sclerosis, Autophagy, Motor system vulnerability, Protein aggregates, Superoxide disumutase-1

\section{Introduction}

Amyotrophic lateral sclerosis (ALS) is an adult-onset neurodegenerative disorder characterized by loss of the upper and lower motor neurons. The disease begins focally and then spreads contiguously, resulting in progressive paralysis and finally death from respiratory failure [45]. Next to C9orf72 [15], the most common known cause of ALS is mutations in the gene of the antioxidant enzyme superoxide dismutase-1 (SOD1), which are found in $2.5-6 \%$ of the cases [1]. SOD1 is ubiquitously expressed, and the cause of the selective vulnerability of the motor system is not understood [30]. Over 180 mutations in SOD1 have been identified in ALS patients (http://alsod.iop.kcl.ac.uk/) [53]. They confer a cytotoxic gain of function to the enzyme, which is also poorly understood. Several of the mutations cause long C-terminal truncations or other disruptive

\footnotetext{
* Correspondence: stefan.marklund@medbio.umu.se

${ }^{1}$ Department of Medical Biosciences, Umeå University, Building 6 M, 2nd

Floor, Umeå SE 901 85, Sweden

Full list of author information is available at the end of the article
}

changes in the expressed protein, precluding native folding. This suggests that any cytotoxicity mechanism that is common to the SOD1 mutants would originate from misfolded SOD1 species.

Inclusions containing aggregated SOD1 are hallmarks of ALS, both in patients and in transgenic animal models expressing mutant human SOD1s (hSOD1) [31]. This fits with a noxious role of hSOD1 un/misfolding, which allows formation of the non-native contacts present in aggregated species [34]. However, it is currently unknown whether the hSOD1 aggregation drives the pathogenesis of ALS, whether it is harmless, and even whether it represents protective scavenging of more toxic soluble misfolded species when the proteostasis is terminally compromised.

Macroautophagy, hereafter called autophagy, is the principal pathway by which cellular protein aggregates are cleared [12]. To gain further insight into the role of aggregation in ALS, we examined autophagy factors in several areas of the CNS in patients and in non-neurological controls and controls with neurodegeneration. We found remarkably low 
content of the key autophagy regulator Beclin 1 and downstream factors in the motor area of spinal ventral horns in the controls, and we also found evidence for activation of autophagy and dysregulation in ALS patients. To investigate the consequences of a low autophagy capacity, the effects of a heterozygous deletion of the Becn1 gene were tested in hSOD1 transgenic mouse models with characteristics resembling ALS in humans. This caused earlier hSOD1 aggregation, onset of symptoms, and motor neuron loss, and also markedly shortened survival. However, there were reduced levels of soluble misfolded hSOD1 species, suggesting that aggregation could be the prime driver of neurotoxicity.

\section{Materials and methods}

\section{Human subjects}

The human study was performed according to the tenets of the Declaration of Helsinki. The collection of human tissues and their use was approved by the Swedish Medical Ethical Review Board. After informed consent from the relatives and whenever possible from the patients, specimens of CNS gray matter, including temporal lobe (ventral $3^{\text {rd }}$ of temporal superior gyrus), frontal lobe (anterior cingulate gyrus), cerebellar vermis, precentral gyrus (hemisphere close to the medial border), and spinal cord, were obtained at autopsy. The dissected segments of the spinal cord included the lamina IX of the ventral horn and the dorsal horn at the cervical or lumbar levels. Altogether, 28 human subjects were examined: five non-neurological controls (mean age at death: $60 \pm 14$ [SD] years, range 43-80 years), five Parkinson's disease (PD) patients (77 \pm 6 years, range $67-82)$, four sporadic ALS (SALS) patients (70 \pm 10 years, range 62-83), five familial ALS (FALS) patients without SOD1 mutations (58 \pm 8 years, range $49-68)$ including four patients with

Table 1 Information on humans subjects used in this study

\begin{tabular}{|c|c|c|c|c|c|}
\hline Case & Diagnosis & Sex & Gene mutation & Age at death (years) & Postmortem delay (hours) \\
\hline 1 & Controls & $M$ & None & 43 & N.A. \\
\hline 2 & Controls & $\mathrm{F}$ & None & 80 & 48 \\
\hline 3 & Controls & $\mathrm{F}$ & None & 64 & 42 \\
\hline 4 & Controls & M & None & 55 & $48-72$ \\
\hline 5 & Controls & M & None & 58 & 29 \\
\hline 6 & SALS & $\mathrm{F}$ & None & 69 & 44 \\
\hline 7 & SALS & $\mathrm{F}$ & None & 83 & $48-72$ \\
\hline 8 & SALS & $\mathrm{F}$ & None & 62 & 52 \\
\hline 9 & SALS & $\mathrm{F}$ & None & 64 & 24 \\
\hline 10 & FALS & M & C9orf72 & 49 & 23 \\
\hline 11 & FALS & M & Not found & 64 & $48-72$ \\
\hline 12 & FALS & M & C9orf72 & 52 & 20 \\
\hline 13 & FALS & $\mathrm{F}$ & C9orf72 & 55 & 13 \\
\hline 14 & FALS & M & C9orf72 & 68 & 50 \\
\hline 15 & FALS & $\mathrm{F}$ & SOD1 A4V & 62 & N.A. \\
\hline 16 & FALS & $\mathrm{F}$ & SOD1 G72C & 73 & N.A. \\
\hline 17 & FALS & M & SOD1 D90A & 75 & 29 \\
\hline 18 & FALS & $\mathrm{F}$ & SOD1 D90A & 64 & 50 \\
\hline 19 & FALS & M & SOD1 D90A & 43 & 32 \\
\hline 20 & FALS & M & SOD1 D90A & 53 & 11 \\
\hline 21 & FALS & M & SOD1 D90A & 66 & 56 \\
\hline 22 & FALS & $\mathrm{F}$ & SOD1 G127X & 62 & 20 \\
\hline 23 & FALS & M & SOD1 G127X & 44 & $36-50$ \\
\hline 24 & PD & M & N.A. & 67 & 52 \\
\hline 25 & PD & $\mathrm{F}$ & N.A. & 82 & $72-96$ \\
\hline 26 & PD & $\mathrm{F}$ & N.A. & 80 & 8 \\
\hline 27 & PD & M & N.A. & 81 & 72 \\
\hline 28 & PD & $\mathrm{F}$ & N.A. & 76 & N.A. \\
\hline
\end{tabular}

SALS sporadic ALS, FALS familial ALS, PD Parkinson's disease, $M$ male, $F$ female, N.A. not available 

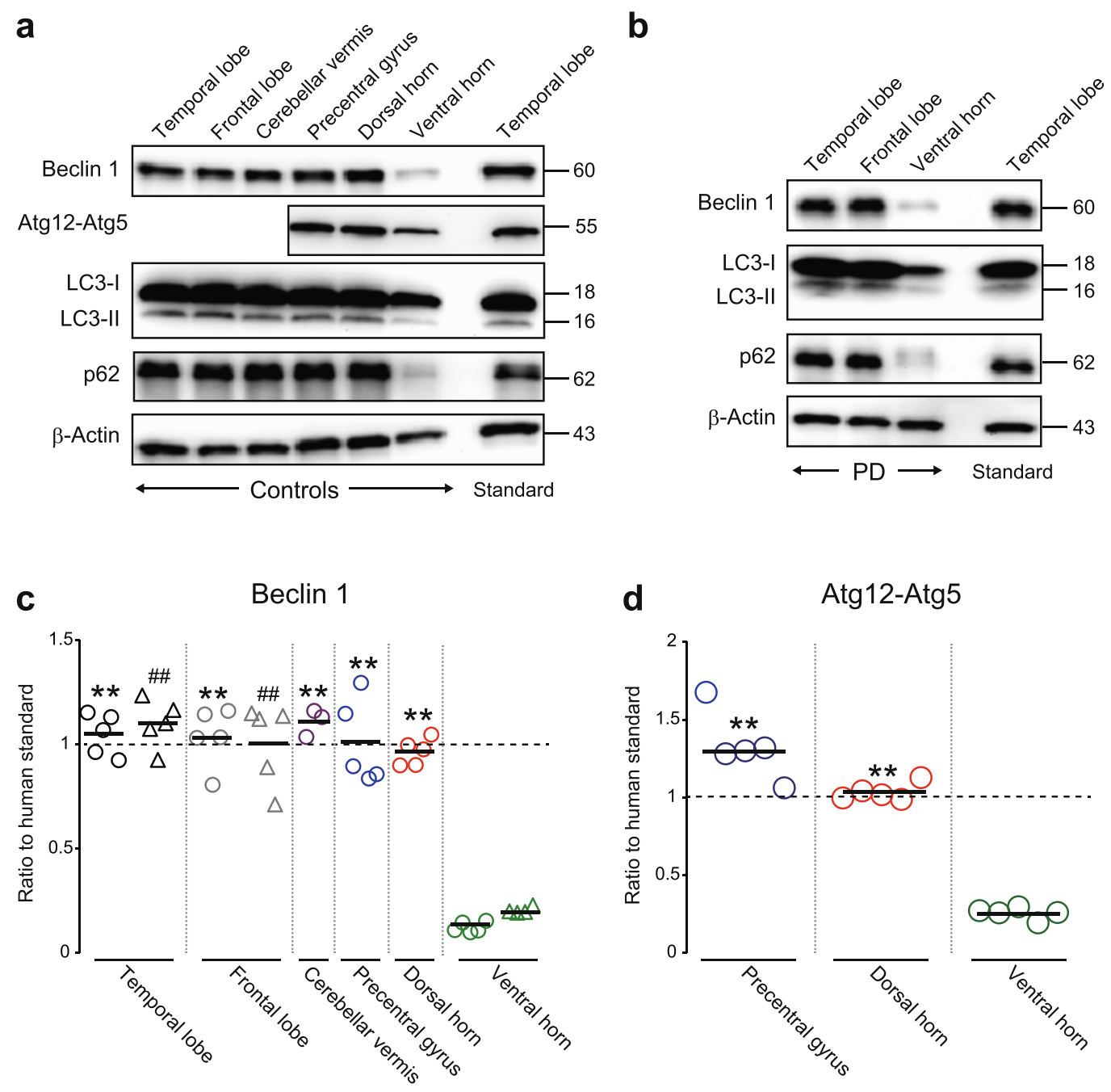

e

LC3-II

f

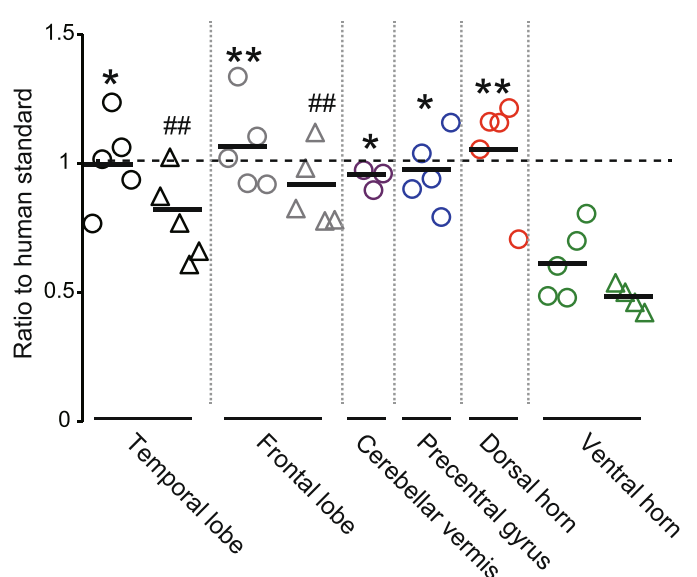

f

p62

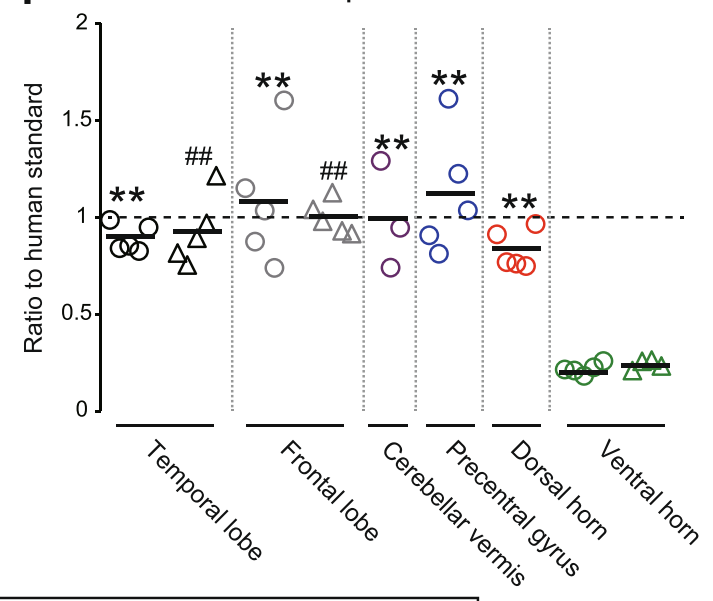

Non-neurological controls $(n=5)$

Parkinson's disease $(n=4-5)$

Fig. 1 (See legend on next page.) 
(See figure on previous page.)

Fig. 1 Autophagy factors are present in exceptionally low amounts in spinal ventral horns of human controls. a, b Western blots for autophagic proteins in human postmortem specimens of distinct CNS regions from (a) non-neurological and (b) neurodegenerative (Parkinson's disease; PD) controls. Aliquots of protein extracts $(20 \mu \mathrm{g})$ were loaded in each well. $\beta$-Actin was used as a loading marker. To allow multiple comparisons between different gels, grey matter from the anterior $3^{\text {rd }}$ of the temporal superior gyrus from a non-neurological control was used as a standard. Triplicate analyses of the proteins were made. Analysis of multiple triplicates indicated a relative standard deviation of the estimates of around $7 \%$. $\mathbf{c}-\mathbf{f}$ Scatter plots showing the expression patterns of autophagic proteins including (c) Beclin 1, (d) Atg12 (detected as Atg12-Atg5 complex), (e) LC3-II, and (f) p62. All values in each CNS region were normalized to the level of expression of the standard. Bars represent mean values. ${ }^{*} P<0.05$ vs. ventral horn of non-neurological controls. ${ }^{*} P<0.01$ vs. ventral horn of non-neurological controls. ${ }^{\# \#} P<0.01$ vs. ventral horn of PD (one-way ANOVA with Tukey-Kramer's test.)

expanded hexanucleotide GGGGCC repeats in C9orf72, and nine FALS patients with SOD1 mutations $(60 \pm$ 11 years, range 43-75) including one A4V [2], one G72C [48], five D90A [30], and two G127 $7^{\text {instggg }}($ G127X) [27, 28]. None of the five ALS patients without SOD1 or C9orf72 mutations carried ALS-associated mutations: all tested negative for a panel of ALS-associated genes including ANG, FUS, OPTN, SQSTM1/p62, TARDBP, TBK1, $U B Q L N 2$, or $V A P B$. All ALS patients fulfilled the revised El Escorial criteria for clinically definite or probable ALS [10]. The postmortem time for all patients varied between 0 and 3 days, and there were no systematic differences among the groups (Table 1).

The CNS tissues were extracted as described previously $[17,30]$. For analysis of the CNS expression patterns of autophagy factors, temporal lobe (ventral $3^{\text {rd }}$ of temporal superior gyrus) from a non-neurological control (case 4, Table 1) was used as a standard to allow multiple comparisons between different gels.

\section{Generation and analyses of ALS model mice with impaired autophagy}

As mouse models of ALS, we used two distinct lines of transgenic mice carrying mutant human SOD1s: hSOD $1^{\text {G127X }}[28]$ and hSOD $1^{\text {G93A }}$ [23]. The hSOD1 ${ }^{\text {G127X }}$ mice were generated in our laboratory (line 716), whereas the hSOD ${ }^{\text {G93A }}$ mice were purchased from Jackson Laboratories (strain name: B6SJLTg(SOD1-G93A)1Gur/J; stock number: 002726). Both lines were back-crossed into a C57BL/6 J background for more than 30 generations.

The mouse strain with a heterozygous deletion of Becn1 was kindly provided by Professor Beth Levine [44]. The Becn1 $1^{+/-}$mice were maintained in a CBA background. Male hSOD $1^{\mathrm{G} 127 \mathrm{X}}$ or $\mathrm{hSOD} 1^{\mathrm{G} 93 \mathrm{~A}}$ mice were crossed with female $B e c n 1^{+/-}$mice. The genotype of the offspring was determined using PCR as described previously [44]. To avoid effects of different genetic backgrounds, non-transgenic and single-mutant mice from the litters were used for comparison with the doublemutant mice.

All animal procedures were carried out according to the guidelines of the Animal Care and Use Committee of the Umeå University. The animal protocols were approved by the Umeå Ethical Committee on Animal Experiments.

\section{Phenotyping of the mice}

The disease courses of the mice were evaluated according to criteria based on changes in body weight [6]. Disease onset was regarded as the time when each mouse reached its peak weight. The endpoint was defined as the age at which a mouse was unable to right itself within $5 \mathrm{~s}$ after being pushed onto its side. The duration of disease was regarded as the period from onset of disease until the endpoint.

The hSOD $1^{\mathrm{G} 127 \mathrm{X}} / \operatorname{Becn} 1^{+/-}$mice and their littermates were analyzed at three distinct stages of the disease: a presymptomatic stage (150 days), a symptomatic stage (10\% weight loss), and a terminal stage $(n=5$ per genotype per disease stage). The hSOD $1^{\text {G93A }} / \mathrm{Becn}^{+/-}$mice and their littermates were examined at a symptomatic stage (10\% weight loss) and a terminal stage $(n=4$ per genotype per disease stage). The lumbar half of the spinal cord was immediately dissected, frozen in liquid nitrogen, and stored at $-80{ }^{\circ} \mathrm{C}$ until use. The spinal cords of mice were extracted in phosphate-buffered saline $(\mathrm{pH} 7.0)$ containing $1 \%(\mathrm{v} / \mathrm{v})$ Nonidet P-40 and EDTA-free Complete ${ }^{\circledR}$ protease inhibitor cocktail (Roche Applied Science) as described previously [51], yielding detergent-soluble and insoluble fractions.

\section{Western immunoblot}

Tissue extracts $(20 \mu \mathrm{g}$ protein) were electrophoresed on Criterion $^{\oplus}$ TGX gels (Any kD; Bio-Rad), and were blotted onto polyvinylidene difluoride membranes (GE Healthcare). The blots were incubated with the following primary antibodies: anti-Beclin 1 (1:10,000; \#3495; Cell Signaling Technology), anti-autophagy related gene (Atg) 12 (1:5,000; \#4180; Cell Signaling Technology), anti- microtubuleassociated protein light chain 3 (LC3) (1:10,000; PM036; Medical \& Biological Laboratories), anti-p62 (1:2,000; 610832; BD Biosciences), anti-lysosome associated membrane protein 2 (Lamp2) (1:10,000; PA1-655; Thermo Scientific), anti-Cathepsin D (1:20,000; ab6313, Abcam), anti-glucose-regulated protein $78 \mathrm{kDa}$ (Grp78) (1:10,000; NB100-91794; Norvus Biologicals), and anti-C/EBP homologous protein (Chop) (1:2,500; sc-575; Santa Cruz 

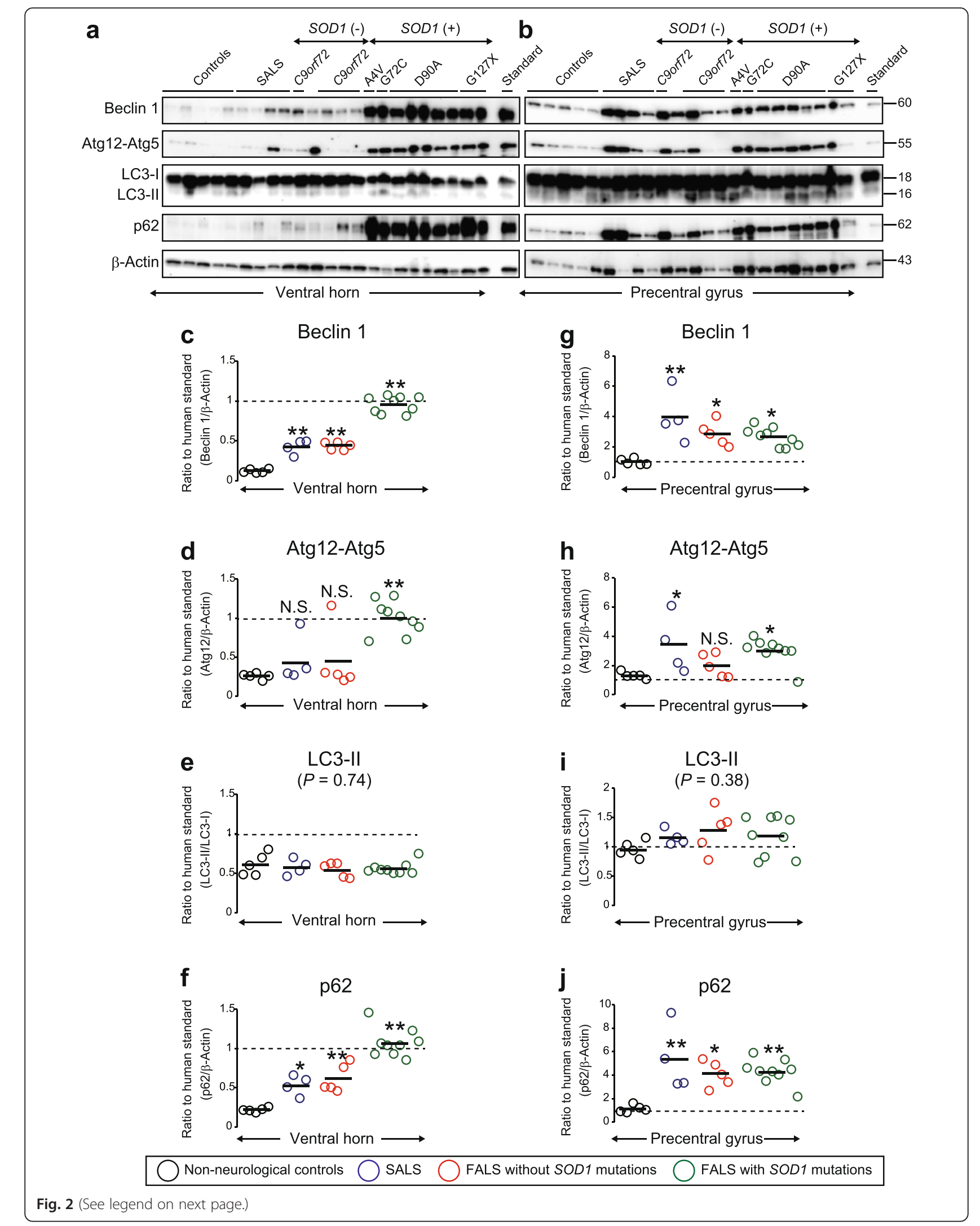
(See figure on previous page.)

Fig. 2 Autophagy factors become elevated in the spinal ventral horns and precentral gyrus of ALS patients. a, b Western blots for autophagic proteins in human postmortem specimens of (a) spinal ventral horns and (b) precentral gyrus from five non-neurological controls, four SALS patients, five FALS patients without SOD1 mutations including expanded hexanucleotide GGGGCC repeats in C9orf72 ( $n=4)$, and nine FALS patients with SOD1 mutations including one A4V, one G72C, five D90A, and two G127X. Aliquots of protein extracts $(20 \mu \mathrm{g})$ were loaded in each well. $\beta$-Actin was used as a loading marker. $\mathbf{c}-\mathbf{j}$ Scatter plots showing the expression levels of autophagic proteins in (c- $\mathbf{f}$ ) ventral horn and $(\mathbf{g}-\mathbf{j})$ precentral gyrus. All values in each CNS region were normalized to the level of expression of the temporal lobe standard. Bars represent mean values. ${ }^{*} P<0.05$ vs. controls. ${ }^{*} P<0.01$ vs. controls. N.S. not significant (vs. controls). Statistical analysis was performed using one-way ANOVA with Tukey-Kramer's test

Biotechnology). $\beta$-Actin (1:50,000; MAB1501R; Millipore) was used as a loading control. For SOD1 analysis, we used anti-hSOD1 $^{\text {G127X }} \quad(0.01 \mu \mathrm{g} / \mathrm{mL}) \quad[28]$, anti-hSOD1 $(0.001 \mu \mathrm{g} / \mathrm{mL}$; human-specific, raised against a peptide corresponding to amino acids 24-39 of hSOD1) [17], or antimurine SOD1 antibodies $(0.1 \mu \mathrm{g} / \mathrm{mL}$, raised against a peptide corresponding to amino acids 24-36 in murine SOD1) [29]. As secondary antibody, horseradish peroxidaseconjugated anti-rabbit or anti-mouse IgG (1:25,000; Dako) was used. The immunoreaction was visualized using an ECL Select reagent (GE Healthcare). The chemiluminescence of the blots was quantified using Quantity One software (Bio-Rad).

\section{Quantification of insoluble ubiquitinated proteins}

Equal volumes of the detergent-insoluble fractions were separated on 4-15\% Criterion ${ }^{\circ}$ TGX gels (Bio$\mathrm{Rad}$ ) and analyzed using western blot with antiubiquitin antibody $(1: 25,000 ;$ Z0458; Dako), which reacts with both Lys48- and Lys63-linked chains [50]. $\beta$-Actin in whole homogenates $(1: 50,000$; MAB1501R; Millipore) was used as an internal marker.

\section{Analysis of hSOD1 aggregates using a filter trap assay}

Amounts of large hSOD1 aggregates in the lumbar half of the spinal cords were quantified using a filter trap assay as described previously [5]. The following primary antibodies were used: anti-hSOD1 ${ }^{\mathrm{G} 127 \mathrm{X}}(0.03 \mu \mathrm{g} / \mathrm{mL})$ [28] and anti-hSOD1 $(0.03 \mu \mathrm{g} / \mathrm{ml}$; raised against a peptide corresponding to amino acids 57-72 of hSOD1) [17]. The aggregate standard (=100 \%) was a homogenate of a spinal cord of a terminally ill hSOD1 ${ }^{\mathrm{G} 93 \mathrm{~A}}$ mouse kept in multiple aliquots in a freezer. The intensity of the staining of the tissue homogenates were related to staining of this standard keeping track of the dilutions used.

\section{Histopathology}

Mice were perfused transcardially with saline followed by $4 \%(\mathrm{w} / \mathrm{v})$ paraformaldehyde in saline $(\mathrm{pH}$ 7.4). The lumbar spinal cords were harvested and embedded in paraffin. The lumbar sections ( $6 \mu \mathrm{m}$ thickness) were immunostained with the following primary antibodies: anti-hSOD1 ${ }^{\mathrm{G} 127 \mathrm{X}}(0.1 \mu \mathrm{g} / \mathrm{mL})$ [28], anti- glial fibrillary acidic protein (GFAP) cocktail $(0.01 \mu \mathrm{g} / \mathrm{mL}$; 556330; BD
Biosciences), and anti- ionized calcium-binding adapter molecule 1 (Iba1) $(0.05 \mu \mathrm{g} / \mathrm{mL}$; 019-19741; Wako Pure Chemicals). The sections were incubated with biotinylated secondary antibody against rabbit IgG or mouse IgG (1:200; Vector Laboratories). The immunoreaction was amplified using the VECTASTAIN ${ }^{\circ} \mathrm{ABC}^{\mathrm{K}}$ Kit (Vector Laboratories) and was detected using 3,3'-diaminobenzidine (Dako) as the chromogen. The sections were imaged using a Pannoramic 250 Flash II scanner (3D Histech Ltd.).

Counting of $\alpha$-motor neurons was performed as described previously [22], with slight revision. Serial transverse sections of the lumbar region were cut with a slice thickness of $6 \mu \mathrm{m}$. To avoid repeated counting of the same $\alpha$-motor neuron, every tenth lumbar section of the spinal cord (L1-L3) was immunostained with anti-NeuN antibody $(1 \mu \mathrm{g} / \mathrm{mL}$; MAB377; Millipore), which does not recognize $\gamma$-motor neurons [19]. The size of the soma of NeuN-positive neurons was measured using Pannoramic Viewer software (3D Histech Ltd.). The number of $\alpha$ motor neurons $\left(>400 \mu^{2}\right)$ in the ventral horn was counted in 10 sections per mouse $(n=3-5$ per genotype).

\section{Measurement of proteasome activities}

The chymotrypsin-like, trypsin-like, and caspase-like activities of proteasome were measured as described elsewhere [49] using a Proteasome-Glo ${ }^{\mathrm{m}}$ Cell-Based Assay Kit (Promega). Background non-specific peptidase activities were determined by adding proteasome inhibitors: bortezomib $(0.1 \mu \mathrm{g} / \mathrm{mL}$ for chymotrypsin-like activity; Calbiochem) or AdaAhx $_{3} \mathrm{~L}_{3} \mathrm{VS}(30 \mu \mathrm{g} / \mathrm{mL}$ for trypsinlike and caspase-like activities; Calbiochem). The proteasome activities were calculated by subtracting the values with the inhibitors (non-specific peptidase) from the values without the inhibitors (total peptidase).

\section{Statistics}

All data are given as mean \pm SD. All statistical tests were performed with Statcel 3 software (OMS Publishing Inc.). Temporal changes in body weight of mice were analyzed using repeated-measures ANOVA. The disease onset and survival of mice were compared using Kaplan-Meier analysis with log-rank test. After validation of data normality 


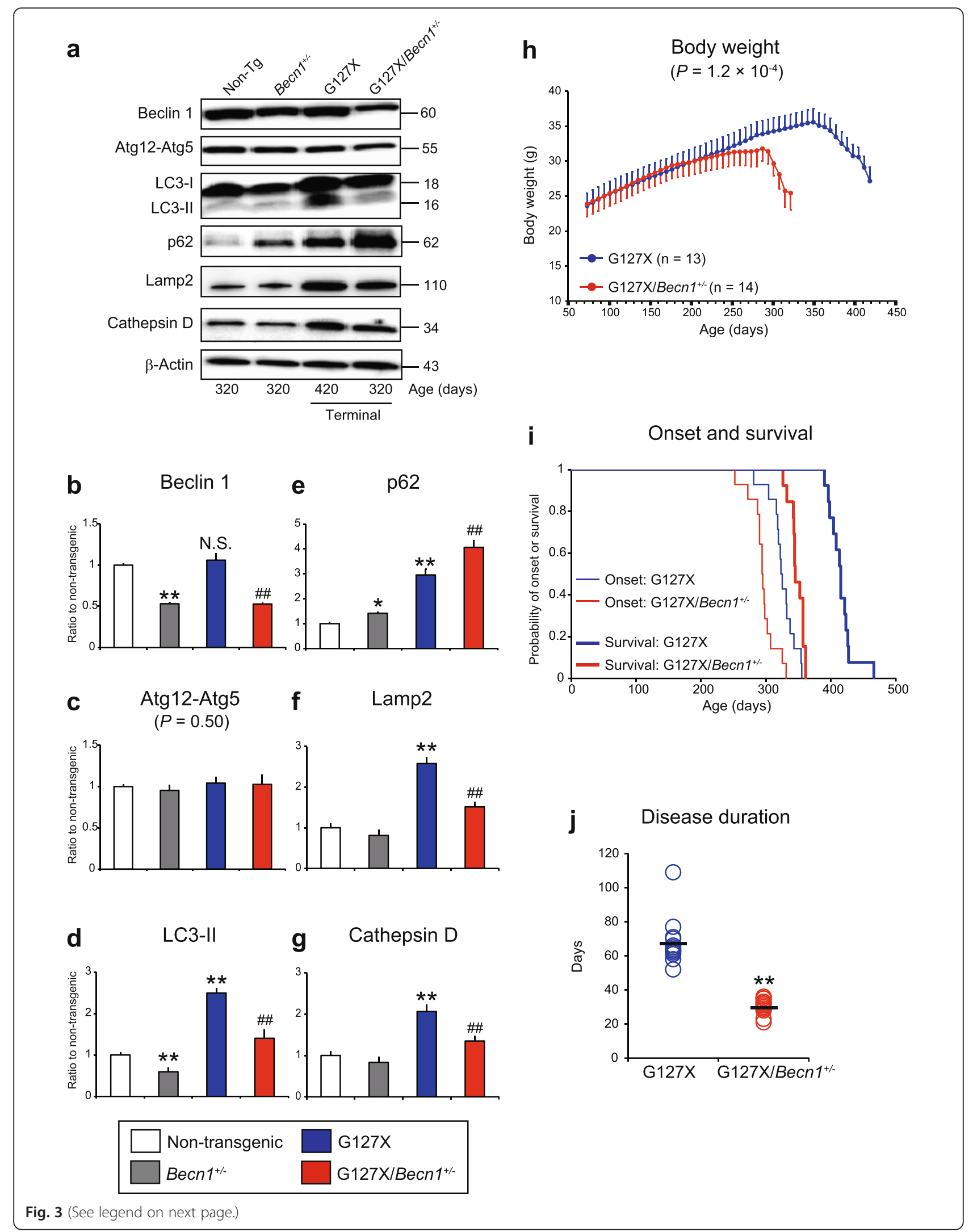


(See figure on previous page.)

Fig. 3 Heterozygous deletion of Becn 1 impairs autophagy and exacerbates the disease course in $\mathrm{hSOD}{ }^{1127 \mathrm{X}}$ mice. a Western blots for autophagic and lysosomal proteins in the spinal cords of $\mathrm{hSOD} 1^{\mathrm{G} 127 \mathrm{X}} / \mathrm{BeC}{ }^{1+/-}$ mice and littermates ( $n=3$ per genotype). $\mathbf{b}-\mathbf{g}$ The relative expression levels of (b) Beclin 1 , (c) Atg12-Atg5, (d) LC3-II, (e) p62, (f) Lamp2, and (g) Cathepsin D in terminally ill mice. Data are given as mean \pm SD. ${ }^{*} P<0.05$ vs Non-Tg. ${ }^{*} P<0.01$ vs Non-Tg. ${ }^{\# \#} P<0.01$ vs. hSOD $1^{\text {G127X }}$ (one-way ANOVA with Tukey-Kramer's test). N.S. not significant (vs. Non-Tg). h-j The disease courses of hSOD ${ }^{\text {G127X }}$ mice

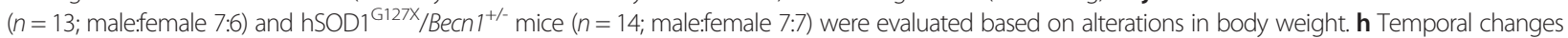
in body weight of the mice. Statistical significance was analyzed using repeated-measures ANOVA. i Kaplan-Meier curves for disease onset and survival. Statistical significance was analyzed using repeated-measures ANOVA using Kaplan-Meier analysis with log-rank test. $\mathbf{j}$ Scatter plot for the disease duration. Bars represent mean values. ${ }^{*} P<0.01$ (two-tailed Welch's $t$-test)

and homoscedasticity, the disease duration was analyzed using a two-tailed Welch's $t$-test. Multiple group comparisons were performed using one-way ANOVA followed by Tukey-Kramer post-hoc test. Statistical significance was defined as $P<0.05$. The " $n$ " values indicate numbers of individual humans or animals but not replicate measures of one sample. All biochemical and histopathological studies were replicated at least twice to validate the findings.

\section{Results}

Exceptionally low concentrations of autophagy factors in human spinal ventral horns

Autophagy factors were analyzed in several areas of the CNS of controls and ALS patients with or without SOD1 mutations. In non-neurological controls, Beclin 1, the principal initiator of autophagy [12], was found to be exceptionally low in lamina IX of the spinal ventral horns as compared to other gray-matter areas of the CNS (Fig. 1a, c). The ventral horn concentrations were equally low in PD patients, a neurodegenerative condition not affecting this area (Fig 1b, c). The levels of the downstream autophagy factors the Atg12-Atg5 complex, the LC3-II, and p62 were also low in the ventral horns of the controls (Fig. 1d, e, f), suggesting a low degree of basal autophagy activity.

In ALS patients, the levels of Beclin 1, Atg12-Atg5, and p62 were modestly elevated, more so in carriers of SOD1 mutations than in apparently sporadic patients and carriers of other ALS-linked mutations (Fig. 2a, c, $\mathrm{d}, \mathrm{f})$. However, the concentrations only approached those found in other areas of the CNS in the control groups (Fig. 1). There were no changes in LC3-II (Fig. 2e). The primary motor cortex in the precentral gyrus, another area affected in ALS, also showed increases in Beclin 1 and p62 expression (Fig. 2b, g, j). The Atg12-Atg5 levels were significantly elevated in SALS and carriers of SOD1 mutations, but not in FALS without SOD1 mutations (Fig. 2h). Again, no changes were found in LC3-II (Fig. 2i). Notably, in the case of the precentral gyrus, the changes were comparatively moderate in carriers of SOD1 mutations.

The autophagy factors were similarly analyzed in spinal dorsal horns, temporal and frontal lobe gray matter, and cerebellar vermis, but in these areas there were no differences between the controls and the ALS groups (Additional file 1: Figure S1).

\section{Heterozygous deletion of Becn 1 in hSOD1 ${ }^{\text {G127X }}$ mice exacerbated ALS-like disease}

To explore the consequence of low autophagy capacity on hSOD1-induced motor neuron disease, the effects of heterozygous deletion of the Becn 1 gene were tested in mice expressing mutant hSOD1s. Homozygous deletion of Becn1 leads to early embryonic lethality, whereas mice with a heterozygous deletion are essentially normal but show impaired autophagy [41, 44]. As our principal model, we chose mice expressing the truncated mutant hSOD $1^{\text {G127X }}$ since it offers several advantages. All of this mutant hSOD1 exists as potentially toxic misfolded monomers in the CNS $[54,55]$. The levels of such species can therefore be directly measured without confounding by the natively folded hSOD1 present in most other transgenic models $[29,54,55]$. Owing to rapid targeting for degradation, the hSOD1 ${ }^{\mathrm{G} 127 \mathrm{X}}$ concentrations are low, less than one-half of those of the endogenous murine SOD1, minimizing the risk of overexpression artifacts $[4,28,29]$. Finally, mimicking ALS in humans, there is a long symptom-free period followed by a middle age onset and a relatively rapid disease course (Fig. 3i).

We verified that activation of autophagy occurred in hSOD $1^{\text {G127X }}$ mice by analysis of autophagy and lysosome factors (Additional file 2: Figure S2). There were no changes in Beclin 1 and Atg12-Atg5, but there were significant increases in LC3-II, p62, Lamp2, and Cathepsin $\mathrm{D}$ already at 150 days, i.e. before onset of symptoms, and further increases at the symptomatic and terminal stages. This is similar to what has been found in other ALS models $[25,56]$. In humans, there were also increases in Beclin-1 and Atg12-Atg5, but not LC3-II, suggesting the existence of some species differences in the autophagic response to SOD1-provoked ALS (Fig. 2c-f). Still, the results suggested that manipulation of autophagy in the mice might give information on the role of the system in aggregate clearance and on the neurotoxic role of the aggregates.

Male hSOD $1^{\text {G127X }}$ mice were crossed with female mice with a heterozygous deletion of Becn1. In the resulting litters, as expected, the Becn1 deletion halved the levels 


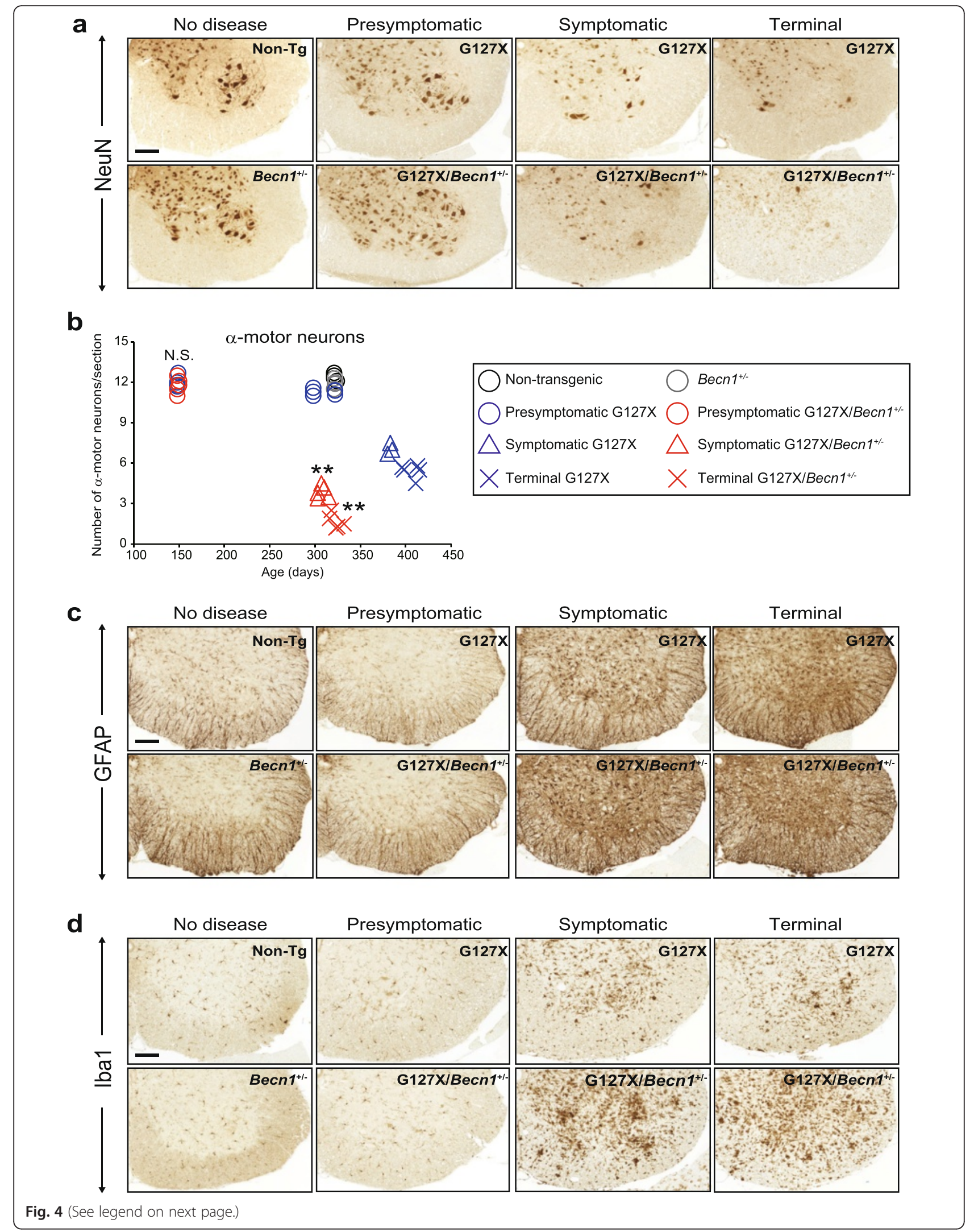


(See figure on previous page.)

Fig. 4 Impaired autophagy worsens ALS-related pathological changes in spinal cords of hSOD $1^{\mathrm{G} 127 \mathrm{X}}$ mice. The hSOD $1^{\mathrm{G} 127 \mathrm{X}} / \mathrm{Becn} 1^{+/}$mice and littermates were analyzed at three distinct stages of the disease: a presymptomatic (150 days), a symptomatic (10\% weight loss), and the terminal stage. The lumbar spinal cord sections were immunostained with antibodies against (a) NeuN, (c) GFAP, or (d) Iba1, which are specific markers for neurons, astrocytes, or microglia, respectively. We used 320-day-old non-transgenic (Non-Tg) and Becn $1^{+-}$mice. b Quantification of NeuN-positive a-motor neurons in the lumbar spinal cords ( $n=3-5$ per genotype). ${ }^{* *} P<0.01$ vs. disease stage-matched hSOD1 ${ }^{\text {G127X }}$. N.S. not significant vs. 150-day-old hSOD1 ${ }^{\text {G127X }}$ (one-way ANOVA with Tukey-Kramer post-hoc test.). Scale bars: $100 \mu \mathrm{m}$

of Beclin 1 regardless of the hSOD1 ${ }^{\text {G127X }}$ transgene (Fig. 3a, b). Although the level of Atg12-Atg5 was not altered (Fig. 3c), there was a $40 \%$ reduction in LC3-II concentration and a $42 \%$ increase in p62 concentration (Fig. 3d, e), suggesting that the reduction in Beclin 1 significantly impaired the autophagic flux in the spinal cords. Additionally, we found that the expression of lysosomal markers, Lamp2 and Cathepsin D, was increased in terminally ill $\mathrm{hSOD} 1^{\mathrm{G} 127 \mathrm{X}}$ mice, but less so in hSOD1 ${ }^{\text {Gi27X }} /$ Becn1 $^{+/-}$mice (Fig. 3f, g). A blocking effect of mutant hSOD1 on maturation of autophagolysosomes might conceivably also have contributed to the patterns observed.

The disease courses of the resulting hSOD $1^{\mathrm{G} 127 \mathrm{X}}$ / Becn $1^{+/-}$mice and hSOD1 ${ }^{\mathrm{G} 127 \mathrm{X}}$ mice were monitored (Fig. 3h-j). Time of onset occurred 53 days earlier in $\mathrm{hSOD} 1^{\mathrm{G} 127 \mathrm{X}} / \mathrm{Becn} 1^{+/-}$mice than in $\mathrm{hSOD} 1^{\mathrm{G} 127 \mathrm{X}}$ mice $\left(295 \pm 19\right.$ vs. $348 \pm 13$ days; $\left.P=5.1 \times 10^{-6}\right)$ (Fig. 3i). The disease duration was 38 days shorter $(30 \pm 4.4$ days vs. $68 \pm 13$ days; $P=7.1 \times 10^{-10}$ ) (Fig. $3 j$ ), and the hSOD $1^{\text {G127X }} /$ Becn $1^{+/-}$mice reached the end stage 90 days earlier than the hSOD $1^{\text {G127X }}$ mice (326 \pm 19 days vs. $416 \pm 19$ days; $P=3.0 \times 10^{-6}$ ) (Fig. $3 \mathrm{i}$ ).

Motor neurons were counted throughout the course of disease (Fig. 4a, b). Earlier and more extensive loss was found in hSOD1 ${ }^{\mathrm{G} 127 \mathrm{X}} / \mathrm{Becn}{ }^{+/-}$mice than in $\mathrm{hSOD} 1^{\mathrm{G} 127 \mathrm{X}}$ mice at the symptomatic stage $\left(43 \pm 3.3 \%\right.$ in $\mathrm{hSOD} 1^{\mathrm{G} 127 \mathrm{X}}$ vs. $70 \pm 3.8 \%$ in $\left.\mathrm{hSOD} 1^{\mathrm{G} 127 \mathrm{X} /} \mathrm{Becn1}^{+/-}, P<0.01\right)$ and at the terminal stage $(57 \pm 4.6 \%$ vs. $87 \pm 4.3 \%, P<0.01)$. In nontransgenic and $B e c n 1^{+/-}$mice, no changes in motor neuron count were seen. The more extensive motor neuron loss in hSOD $1^{\text {G127X }} /$ Becn $1^{+/-}$mice was accompanied by enhanced numbers and activation of astrocytes and microglia at the symptomatic and terminal phases (Fig. 4c, d).

Thus, deletion of even a single allele of Becn 1 in hSOD $1^{\text {G127X }}$ mice results in exacerbation of the disease course-including onset, duration, lifespan, and loss of spinal motor neurons.

Since Beclin 1 is a haplo-insufficient tumor suppressor gene, Becn $1^{+/-}$mice develop tumors in several tissues including the lungs and liver when over 400 days old. These can be detected even by gross morphology [44]. To exclude the possibility that exacerbation of the disease course in $\mathrm{hSOD} 1^{\mathrm{G} 127 \mathrm{X}} / \mathrm{Becn} 1^{+/-}$mice was associated with development of tumors, we examined the gross appearance of lungs and liver from terminally ill
hSOD $1^{\mathrm{G} 127 \mathrm{X}} / \mathrm{Becn}^{+/-}$mice, age-matched Becn $1^{+/-}$mice and non-transgenic mice (Additional file 3: Figure S3a). No changes were found. The rise in body weight in Becn $1^{+/-}$mice ( $n=8$; male:female 4:4) was essentially identical to that in non-transgenic mice $(n=10$; male:female $4: 6)$, at least until 320 days of age $(P=0.56)$, which was the mean lifespan of hSOD $1^{\mathrm{G} 127 \mathrm{X}} / \mathrm{Becn} 1^{+/-}$ mice (Additional file 3: Figure S3b).

\section{Heterozygous deletion of Becn 1 in $\mathrm{hSOD} 1^{\mathrm{G} 127 \mathrm{X}}$ mice increased aggregated and decreased soluble mutant hSOD1}

The total concentration of hSOD $1^{\mathrm{G} 127 \mathrm{X}}$ in spinal cords rose with time; at all ages, it was higher in $\mathrm{hSOD} 1^{\mathrm{G} 127 \mathrm{X}}$ / Becn $1^{+/-}$mice than in hSOD1 ${ }^{\text {G127X }}$ mice (Fig. 5a, b). This was caused by increased levels of detergentinsoluble hSOD1 ${ }^{\text {G127X }}$ (Fig. 5c), which were higher in $\mathrm{hSOD} 1^{\mathrm{G} 127 \mathrm{X}} / \mathrm{Becn} 1^{+/-}$mice than in $\mathrm{hSOD} 1^{\mathrm{G} 127 \mathrm{X}}$ mice. Even when compared at the same disease stages, the concentrations were higher in $\mathrm{hSOD} 1^{\mathrm{G} 127 \mathrm{X}} / \mathrm{Becn} 1^{+/-}$ mice: 2.0-fold and 1.6-fold at the symptomatic and terminal stages, respectively. In contrast, the concentrations of soluble hSOD1 ${ }^{\text {G127X }}$ declined with time and at all stages they were lower in $\mathrm{hSOD} 1^{\mathrm{G} 127 \mathrm{X}} / \mathrm{Becn} 1^{+/-}$mice than in hSOD1 ${ }^{\text {G127X }}$ mice (Fig. 5d). As an independent method for analysis of hSOD1 aggregates, the spinal cord homogenates were analyzed with a dot-blot filter assay (Fig. 5e). The time-course patterns were very similar to those of the detergent-insoluble $\mathrm{hSOD} 1^{\mathrm{G} 127 \mathrm{X}}$ species.

The hSOD1 ${ }^{\text {G127X }}$ mutant in lumbar spinal cords was also examined by immunohistochemistry (Fig. 5f). At the presymptomatic stage, the highest levels of the protein were seen in the vulnerable $\alpha$-motor neurons of the ventral horn. Other cell populations were more faintly stained. At the symptomatic and terminal stages, punctate aggregates also accumulated in the neuropil. The levels were clearly higher in the $\mathrm{hSOD} 1^{\mathrm{G} 127 \mathrm{X}} / \mathrm{Becn} 1^{+/-}$mice.

To test the possibility that the drastic alterations in hSOD $1^{\text {G127X }}$ fractions might to any degree be caused by changes in SOD1 synthesis in the compromised spinal cord, the endogenous murine SOD1 was analyzed with a mouse-specific antibody (Additional file 4: Figure S4). No changes in concentration were found and it was soluble: detergent-insoluble/aggregated murine SOD1 could not be demonstrated at any of the disease stages. This is 


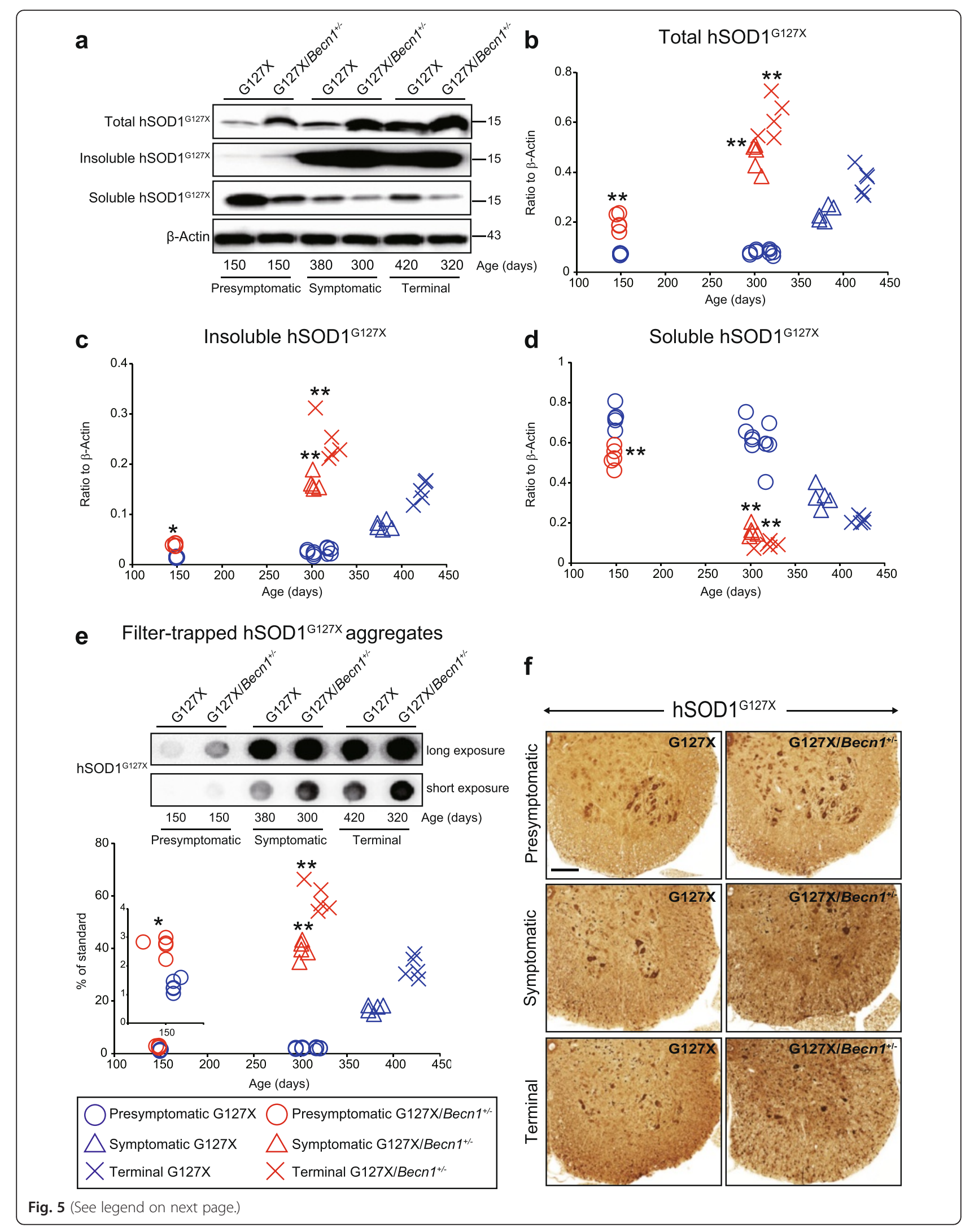


(See figure on previous page.)

Fig. 5 Impaired autophagy increases hSOD1 ${ }^{\mathrm{G} 127 \mathrm{X}}$ aggregation, and reduces the amount of soluble species throughout the disease course. The spinal cords ( $n=5$ per genotype per disease stage) were separated into three distinct fractions based on detergent solubility: whole homogenates, detergent-insoluble, and detergent-soluble fraction. a Western blots for hSOD1 ${ }^{\mathrm{G} 127 \mathrm{X}}$ protein in the three fractions. $\beta$-Actin in whole homogenates was used as a loading control. b-d Amounts of (b) total, (c) insoluble, and (d) soluble hSOD1 ${ }^{\mathrm{G} 127 \mathrm{X}}$ protein. ${ }^{*} P<0.05 \mathrm{vs}$. hSOD $1^{\mathrm{G} 127 \mathrm{X}}$ mice at 150 days of age. ${ }^{* * P} P 0.01$ vs. disease stage-matched $\mathrm{hSOD} 1^{\mathrm{G} 127 \mathrm{X}}$ mice (one-way ANOVA with Tukey-Kramer's test). e Upper: Filter-trapped hSOD $1^{\mathrm{G} 127 \mathrm{X}}$ aggregates in the spinal cords of the mice ( $n=5$ per genotype per disease stage). Lower. Amounts of $h S O D 1^{G 127 X}$ aggregates. ${ }^{*} P<0.05$ vs. hSOD $1^{G 127 X}$ mice at 150 days of age. ${ }^{*} P<0.01$ vs. disease stage-matched hSOD $1^{G 127 X}$ mice (one-way ANOVA with Tukey-Kramer's test). $\mathbf{f}$ Immunohistochemistry for hSOD $1^{\text {G127X }}$ protein in lumbar spinal cords of mice. Scale bars: $100 \mu \mathrm{m}$

in accord with previous studies showing that human and murine SOD1s do not coaggregate $[5,21]$.

\section{Equal degrees of ER stress in terminal $\mathrm{hSOD} 1^{\mathrm{G} 127 \mathrm{X}}$ mice and $\mathrm{hSOD} 1^{\mathrm{G} 127 \mathrm{X}} / \mathrm{BeCn} 1^{+/-}$mice}

Endoplasmic reticulum (ER) stress, a condition in which misfolded proteins accumulate in the lumen of the ER, has been implicated in the pathogenesis of mutant hSOD1 mouse models and ALS patients [3]. We analyzed the ER stress markers Grp78 and Chop, and found increases in terminally ill mice (Additional file 5: Figure S5). The final degree of activation was equal, but the stage analyzed appeared earlier in $\mathrm{hSOD} 1^{\mathrm{G} 127 \mathrm{X}} / \mathrm{Becn}^{+/-}$mice than in $\mathrm{hSOD} 1^{\mathrm{G} 127 \mathrm{X}}$ mice.

\section{Exacerbated disease also in $\mathrm{hSOD} 1^{\mathrm{G} 93 \mathrm{~A}} / \mathrm{Becn} 1^{+/-}$mice}

Mice that express G93A mutant hSOD1 are the most commonly examined murine ALS model [23]. The model is aggressive, with early onset of symptoms and a short lifespan. The concentration of mutant hSOD1 is 17-fold higher than that of the endogenous murine SOD1, causing overexpression artifacts $[4,29]$. Moreover, over $95 \%$ of the protein is natively folded, making analysis of misfolded hSOD1 conformers complicated [54, 55]. For reference purposes, we performed a limited study of the effects of Becn1 deletion using this model (Fig. 6).

The time of onset was not significantly different in $\mathrm{hSOD} 1^{\mathrm{G} 93 \mathrm{~A}}$ mice and $\mathrm{hSOD} 1^{\mathrm{G} 93 \mathrm{~A}} /$ Becn $^{+/-}$mice $(121 \pm$ 3.6 days vs. $125 \pm 2.7$ days; $P=0.23$; Fig. 6 a). However, the disease duration was much shorter ( $52 \pm 4.8$ days vs. $31 \pm$ 4.6 days; $P=5.7 \times 10^{-9}$; Fig. $\left.6 \mathrm{~b}\right)$, leading to shortened survival (173 \pm 5.7 days vs. $156 \pm 4.6$ days; $P=2.0 \times 10^{-4}$; Fig. 6a).

As with the hSOD1 ${ }^{\mathrm{G} 127 \mathrm{X}}$ model, the amount of aggregated hSOD1 was higher in $\mathrm{hSOD} 1^{\mathrm{G} 93 \mathrm{~A}} / \mathrm{Becn}^{+/-}$mice than in hSOD1 ${ }^{\mathrm{G} 93 \mathrm{~A}}$ mice at both the symptomatic stage and the terminal stage (Fig. $6 \mathrm{c}, \mathrm{d}, \mathrm{f}$ ). In contrast to the hSOD $1^{\mathrm{G} 127 \mathrm{X}}$ mice, no changes could be discerned in the huge amounts of total and soluble hSOD $1^{\mathrm{G} 93 \mathrm{~A}}$ mutant present in the spinal cords (Fig. 6e).

Other changes were generally comparable to those in $\mathrm{hSOD1}^{\mathrm{G} 127 \mathrm{X}} /$ Becn $^{+/-}$mice, including autophagy factors, lysosomal markers, murine SOD1 expression, and ER stress markers (Additional file 4: Figure S4, Additional file 5: Figure S5 and Additional file 6: Figure S6).

\section{Larger increases in ubiquitinated insoluble proteins in hSOD $1^{\text {G93A }}$ mice than in hSOD ${ }^{\text {G127X }}$ mice}

The proteasome is the main pathway for degradation of ubiquitinated proteins. However, autophagy also has a role in the clearance of such proteins [46]. We thus quantified the amounts of ubiquitinated insoluble proteins (Fig. 7). The heterozygous deletion of Becn1 did not in itself increase the concentration. In terminally ill hSOD $1^{\text {G127X }}$ and hSOD ${ }^{\text {G93A }}$ mice, the levels were significantly increased, and these increases were enhanced by the Becn 1 deletion (Fig. 7c, d). Remarkably, irrespective of Beclin 1 status, the increases were more than double as high in hSOD $1^{\mathrm{G} 93 \mathrm{~A}}$ mice as in $\mathrm{hSOD} 1^{\mathrm{G} 127 \mathrm{X}}$ mice (Fig. 7a, b). The increases are not explained by impairments of the proteolytic activities of the proteasome (Additional file 7: Figure S7).

\section{Discussion}

A main finding in the present study was the low Beclin 1 concentration in lamina IX of the spinal ventral horns from the two control groups. The other gray matter areas examined, including the dorsal horns, contained around seven times more Beclin 1 and, overall, they were similar to each other. In accord with the low Beclin 1 levels, there were also remarkably low concentrations of the downstream autophagy factors the Atg12-Atg5 complex, LC3-II and p62. The motor neuron demise caused by mutant SOD1 is partly non-cell autonomous since it is influenced by the presence of the mutant protein also in the surrounding glia [26]. Motor neuron somata and neurites have been estimated to occupy $20 \%$ of the volume of the ventral horns [11], and together with supporting glia, they should account for a major proportion of the specimens analyzed here. Thus, low levels of autophagy factors should be a characteristic of the cells that form the spinal motor system. The cortical upper motor neurons are sparse in the gray matter of the precentral gyrus, and they would occupy a minor proportion of the volume. Thus, we cannot draw any firm conclusions regarding the autophagy capacity of the cells that form the upper motor system. 


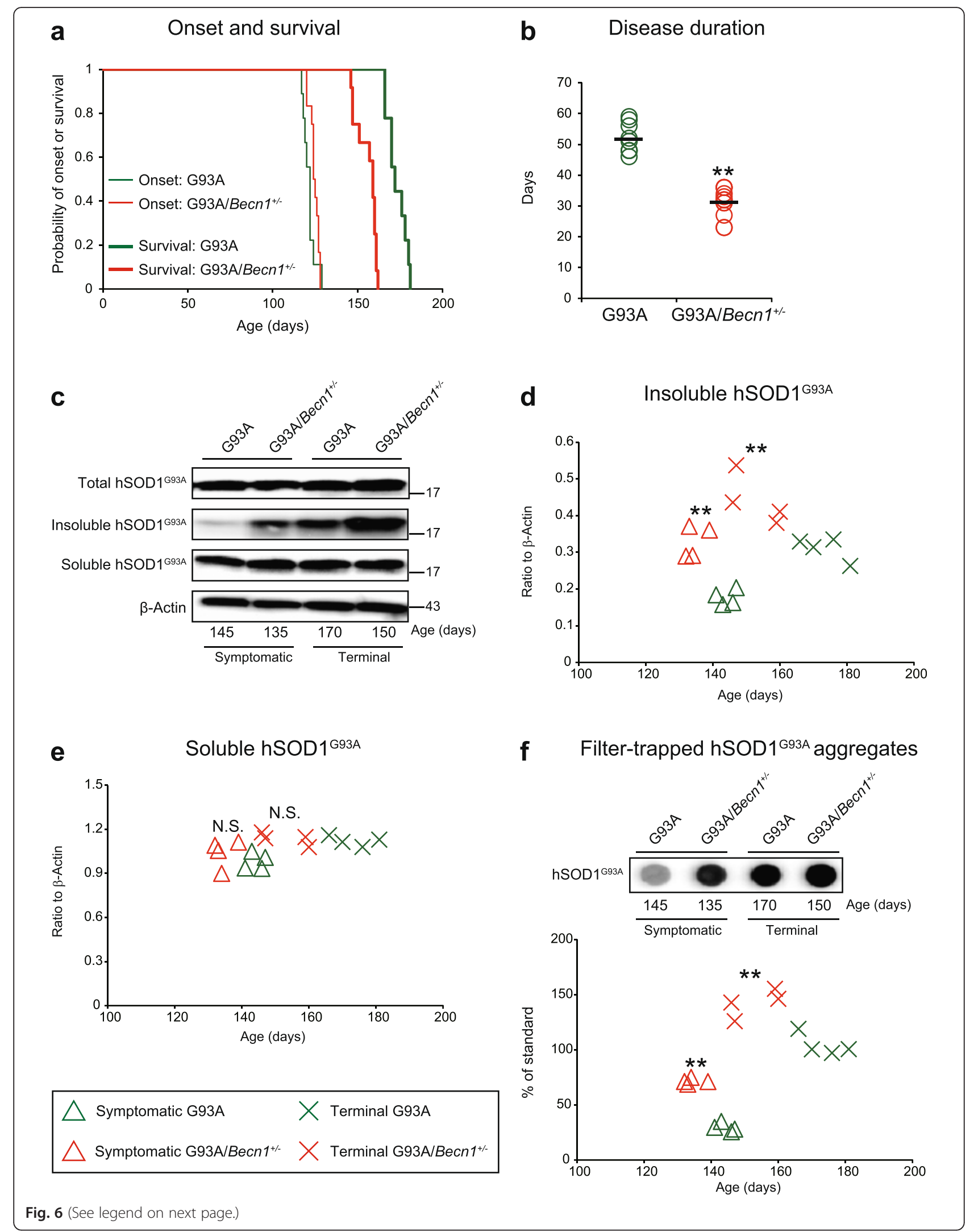




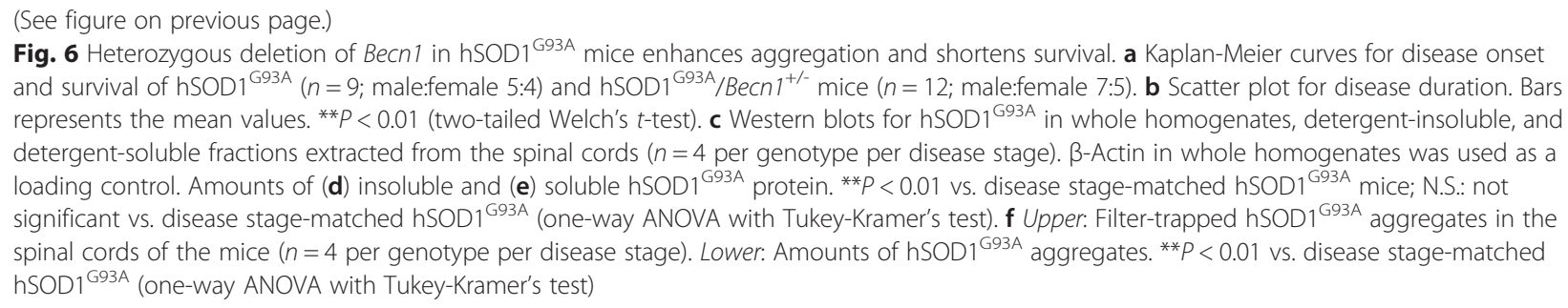

In the ALS patients, there was evidence of some activation of autophagy, both in the ventral horns and in the precentral gyrus. Notably, the subgroup carrying SOD1 mutations showed the greatest changes in the spinal ventral horns, whereas the increases in the precentral gyrus were more comparable in all ALS forms. This is in accord with the lower motor neuron emphasis in ALS patients with SOD1 mutations [2]. Despite the increases in the autophagy initiator Beclin 1 and the Atg12-Atg5 complex, there was no evidence of autophagy activation in terms of LC3-II elevations. Furthermore, the adaptor protein $\mathrm{p} 62$, which is degraded together with protein aggregates in autolysosomes [32], was accumulated, suggesting that the autophagic flux might be impeded in ALS. Thus, our findings might indicate a degree of autophagy dysfunction, particularly in mutant SOD1induced ALS.

Inclusions containing misfolded SOD1 are found in not only patients carrying SOD1 mutations, but also in both sporadic and familial cases that carry other ALS-linked mutant proteins $[8,16,17,21]$. This suggests that the protein may be more generally involved in ALS. In this regard, it is noteworthy that the granular SOD1 inclusions within motor neurons of SALS patients colocalized partially with lysosomal markers [17], which supports the present evidence of dysregulation of autophagy in the disease.

We found here that a moderate reduction in autophagy by $\mathrm{Becn}^{+/-}$caused more aggressive disease in hSOD $1^{\text {G127X }}$ ALS model mice. There was earlier onset, faster progression, and a markedly shortened lifespan. In accord with the accelerated disease course, there was also an earlier and more extensive loss of motor neurons. It is notable that in the terminal stage the loss was greater in the double mutant mice than in the hSOD $1^{\mathrm{G} 127 \mathrm{X}}$ mice. It has been found that paralysis can be caused by both loss of motor neurons and dysfunction of remaining motor neurons [20]. Perhaps the latter mechanism played a proportionally greater role in the hSOD $1^{\mathrm{G} 127 \mathrm{X}}$ mice. In parallel, an enhanced aggregation of hSOD $1^{\mathrm{G} 127 \mathrm{X}}$ was found, showing the importance of autophagy in elimination of protein aggregates. In contrast, the concentration of soluble hSOD ${ }^{\mathrm{G} 127 \mathrm{X}}$, which exists entirely as misfolded monomers [54, 55], was lower from the presymptomatic stage to the end stage. This is not explained by alterations in the proteasome, which is the primary system for degradation of misfolded proteins: the activity did not change during the course of the disease, and did not differ between the two mouse types. Nor do the alterations seem to stem from any changes in synthesis of SOD1 in compromised spinal cord: the concentration of the endogenous murine SOD1 was constant throughout the course of disease. Autophagy is thought to be responsible for turnover of long-lived proteins in the cytosol, but it apparently has no significant role in degradation of murine SOD1, which has a comparatively long half-life of 20 days in the CNS [42]. We propose that the lower concentrations of soluble misfolded $\mathrm{hSOD} 1^{\mathrm{G} 127 \mathrm{X}}$ in the $\mathrm{hSOD} 1^{\mathrm{G} 127 \mathrm{X}}$ / $B e c n 1^{+/-}$mice result from high rates of recruitment into free fibril edges in the abundant hSOD1 aggregates (this is discussed in supplementary data in [35]). The findings are compatible with the notion that soluble, misfolded SOD1 species provoke ALS through formation of aggregates rather than through direct effects on critical components in motor-area cells. Whether this conclusion would hold for all ALS-linked SOD1 mutants is unknown, but in our view it is more likely that they all cause the disease by the same basic mechanism rather than through several individual ones.

Beclin 1 exerts its role in autophagy induction by being a membrane-bound scaffold which enables the recruitment of other autophagy proteins involved in nucleation and maturation of the autophagosome [12]. By binding to various specific proteins, Beclin can also localize to and regulate other vesicle trafficking pathways [37]. Weakening of these may have contributed to the phenotypes observed in the $B e c n 1^{+/}$mice. Retromer trafficking is impaired in such mice leading to reduced phagocytosis of extracellular aggregates by microglia [36]. This may have contributed to the greater aggregate accumulation in the hSOD1 transgenic mice with the heterozygous Becn1 deletion than in those without when compared at the same disease stages. Via binding to the UV radiation resistance-associated gene protein (UVRAG), Beclin 1 can localize to and regulate various endocytic pathways, and this function is important for the integrity of neurons [38]. Conditional Becn1 


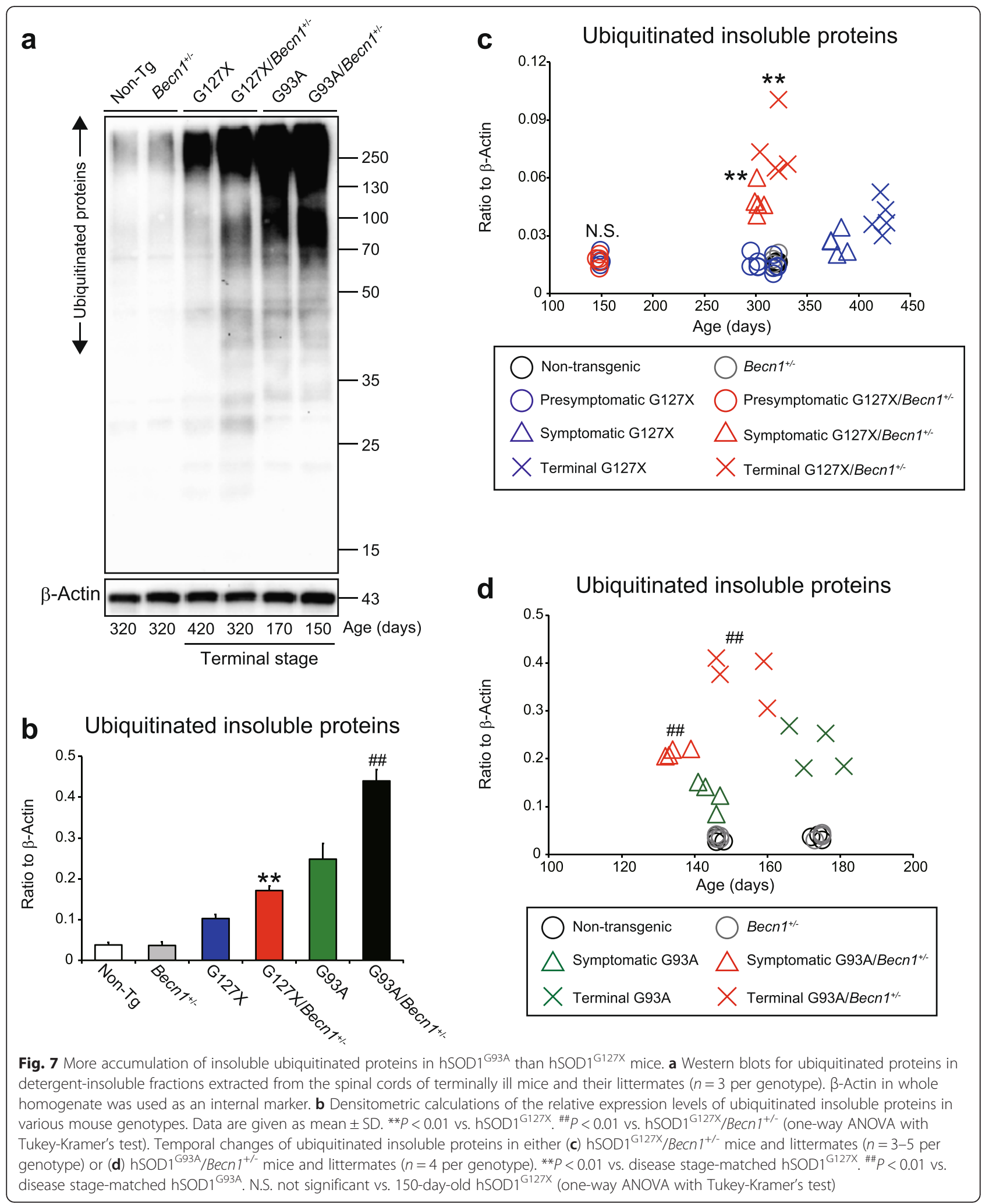

knockout in neurons leads to impairment of endocytic pathways and accelerated neurodegeneration [38]. The degree of such impairment in mice with a heterozygous
Becn1 deletion is not known, but we cannot exclude some role in the exacerbated phenotypes of the present double mutant mice. 
A further potential confounding mechanism is the binding of Beclin-1 to the antiapoptotic factors Bcl-2 and $\mathrm{Bcl}-\mathrm{X}_{\mathrm{L}}$ in the ER. Beclin 1 is inactive when present in such complexes and to exert its activities it has to be released, which can be accomplished by a variety of mechanisms [40]. The complex formation does, however, not seem to interfere with the activity of the antiapoptotic factors, and there is no convincing evidence that Beclin 1 can serve as a proapoptotic factor [13, 47]. Thus, it would appear less likely that any reduced crosstalk with the apoptotic system influenced the disease in the hSOD $1^{\mathrm{G} 127 \mathrm{X}} /$ Becn $^{+/-}$mice.

The results in the $\mathrm{hSOD} 1^{\mathrm{G} 127 \mathrm{X}} / \mathrm{Becn} 1^{+/-}$mice were corroborated in the more aggressive hSOD $1{ }^{\mathrm{G} 93 \mathrm{~A}}$ model, although the effects of the heterozygous Becn1 deletion were smaller. The Becn 1 deletion was even recently reported to amend the disease in mice expressing G86R mutant murine SOD1 [39]. Curiously, there was a nonsignificant delay in onset of symptoms, but a shortened symptomatic phase, together resulting in a 14-day prolongation of survival. Perhaps the Becn1 deletion by some mechanism delayed the initiation of the murine SOD1 ${ }^{\text {G86R }}$ aggregation, but still reduced the clearance of aggregates once the process was under way. The unexpected result may also be related to the fact that this transgenic model is even more aggressive than the hSOD $1^{\mathrm{G} 93 \mathrm{~A}}$ model. We found much greater increases in ubiquitinated insoluble proteins in the $\mathrm{hSOD} 1^{\mathrm{G} 93 \mathrm{~A}}$ model than in the hSOD1 ${ }^{\mathrm{G} 127 \mathrm{X}}$ model. Part of the increases might be related to increased accumulation p62 owing to autophagy inhibition. Such increased p62 has been shown to inhibit delivery of substrate to the proteasome [33]. The increases in p62 were, however, comparable in the hSOD $1^{\mathrm{G} 93 \mathrm{~A}}$ and $\mathrm{hSOD} 1^{\mathrm{G} 127 \mathrm{X}}$ models. Perhaps a greater load of aggregated proteins in the highly aggressive models leads to insufficiency in autolysosomal clearance [7]. In that situation, a high degree of autophagy flux might have negative effects, e.g. by enhancing lysosomal membrane destabilization [9]. Other explanations for the discrepancy could be that the SOD $1^{\mathrm{G} 86 \mathrm{R}}$ mutant was murine and that it also affected another segment of the SOD1 protein. Thus, it cannot be excluded that the consequences of altering Beclin-1 levels and autophagic capacity may differ between both mouse models and different ALS patients.

The current findings may also shed light on the vulnerability of the motor system to mutations in other ubiquitously expressed proteins. Thus, mutations in $V C P$, OPTN, UBQLN2, CHMP2B, SQSTM1/p62, DCTN1 [43], $T B K 1[14,18]$ have all been suggested to cause impairment of the autophagy-lysosomal system [24]. Mutations in TARDBP, FUS, and C9orf72 are all associated with potentially toxic protein aggregation [24]. Although the anatomical conditions only allowed assessment of the spinal motor system, the inherent low autophagy activity detected might contribute to the selective vulnerability both to aggregation-prone proteins and to mutations that further depress the autophagy-lysosomal pathway.

\section{Conclusions}

The results of the study suggest that an inherent low autophagy capacity might cause the selective vulnerability of the motor system to mutant SOD1s, and that aggregation of the protein plays a crucial role in the pathogenesis. The findings may also explain the vulnerability to mutations in other proteins expected to weaken the autophagy-lysosomal pathway. This suggests that measures aimed at enhancing this pathway might be beneficial in treatment of ALS. The interventions which have been tested so far in preclinical systems and in patients have, however, yielded ambiguous results perhaps calling for development of new concepts [52].

\section{Additional files}

Additional file 1: Figure S1. No alterations in autophagic status in spinal dorsal horn, temporal lobe, frontal lobe, and cerebellar vermis from ALS patients. (EPS $1998 \mathrm{~kb}$ )

Additional file 2: Figure S2. Alterations in autophagy and lysosome factors in spinal cords of hSOD $1^{\text {G127X }}$ mice over the course of disease. (EPS $2037 \mathrm{~kb}$ )

Additional file 3: Figure S3. Exacerbation of the disease course in hSOD $1^{\mathrm{G} 127 \mathrm{X}} / \mathrm{BeCn}^{+/}$mice does not result from the development of tumors. (EPS $14820 \mathrm{~kb}$ )

Additional file 4: Figure S4. Impaired autophagy does not influence the amounts of murine SOD1. (EPS $2296 \mathrm{~kb}$ )

Additional file 5: Figure S5. Equal degrees of ER stress in terminal mutant hSOD1 mice irrespective of Beclin 1 status. (EPS 2004 kb)

Additional file 6: Figure S6. Heterozygous deletion of Becn 1 impairs autophagy in hSOD1 ${ }^{\text {G93A }}$ mice. (EPS $2220 \mathrm{~kb}$ )

Additional file 7: Figure S7. The proteolytic function of the proteasome is not impaired in in Becn $1^{+/}$mice carrying hSOD1 mutants. (EPS $1730 \mathrm{~kb})$

\section{Abbreviations}

ALS: Amyotrophic lateral sclerosis; Atg: Autophagy related protein; Chop: C/EBP homologous protein; ER: Endoplasmic reticulum; FALS: Familial ALS; GFPA: Glial fibrillary acidic protein; Grp78: Glucose-regulated protein 78 kDa; G127X: Gly127 $7^{\text {instgg9; }}$ hSOD1: Human SOD1; Iba1: Ionized calcium-binding adapter molecule 1; Lamp2: Lysosome associated membrane protein 2; LC3: Microtubule-associated protein light chain 3; PD: Parkinson's disease; SALS: Sporadic ALS; SOD1: Superoxide dismutase-1.

Competing interests

E.T. and T.B. declare no conflicts of interest. P.M.A. and S.L.M. receive personal fees from Biogen IDEC outside the submitted work.

\section{Authors' contributions}

SLM supervised the entire research project and designed the experiments. PMA performed genetic screening of human subjects and recruited autopsies. TB performed autopsies on human subjects. ET performed the experiments. ET and SLM analyzed the data and wrote the manuscript. All authors were participants in the discussion of results, determination of conclusions, and review of the manuscript. All authors read and approved the final manuscript. 


\section{Acknowledgments}

We thank Professor Beth Levine (University of Texas Southwestern Medical Center, Dallas, TX, USA) for kindly providing the Becn $1^{+/-}$mouse strain. We are also grateful to Dr. Karin S. Graffmo, Dr. Per Zetterström, Eva Bern, Karin Hjertkvist, Ulla-Stina Spetz, Agneta Öberg, Ann-Charloth Nilsson, and Dr Bente Pakkenberg (Bispebjerg and Frederiksberg Hospital, Copenhagen, Denmark) for assistance.

\section{Funding}

The study was supported by the Swedish Research Council, the Knut and Alice Wallenberg Foundation, the Bertil Hållsten Brain Foundation, the Torsten and Ragnar Söderberg Foundation, the the Umeå University Strategic Neuroscience Program, the Kempe Foundations, Västerbotten County Council, Neuroforbundet, and Ulla-Carin Lindquist Foundation.

\section{Author details}

'Department of Medical Biosciences, Umeå University, Building $6 \mathrm{M}$, 2nd Floor, Umeå SE 901 85, Sweden. ${ }^{2}$ Department of Pharmacology and Clinical Neuroscience, Umeå University, Umeå SE 901 85, Sweden. ${ }^{3}$ Present Address: Department of Chemistry, Keio University, 3-14-1, Hiyoshi, Yokohama 223-0061Kanagawa, Japan.

Received: 9 January 2016 Accepted: 9 January 2016 Published online: 25 January 2016

\section{References}

1. Andersen PM, Al-Chalabi A. Clinical genetics of amyotrophic lateral sclerosis: what do we really know? Nat Rev Neurol. 2011;7:603-15. doi:10.1038/nrneurol.2011.150.

2. Andersen PM, Nilsson P, Keranen ML, Forsgren L, Hagglund J, Karlsborg M, et al. Phenotypic heterogeneity in motor neuron disease patients with CuZn-superoxide dismutase mutations in Scandinavia. Brain. 1997;120:1723-37. doi:10.1093/brain/ 120.10.1723.

3. Atkin JD, Farg MA, Walker AK, McLean C, Tomas D, Horne MK. Endoplasmic reticulum stress and induction of the unfolded protein response in human sporadic amyotrophic lateral sclerosis. Neurobiol Dis. 2008;30:400-7. doi:10.1016/j.nbd.2008.02.009.

4. Bergemalm D, Jonsson PA, Graffmo KS, Andersen PM, Brannstrom T, Rehnmark A, et al. Overloading of stable and exclusion of unstable human superoxide dismutase-1 variants in mitochondria of murine amyotrophic lateral sclerosis models. J Neurosci. 2006;26:4147-54. doi:10.1523/jneurosci.5461-05.2006.

5. Bergh J, Zetterström P, Andersen PM, Brännström T, Graffmo KS, Jonsson PA, et al. Structural and kinetic analysis of protein-aggregate strains in vivo using binary epitope mapping. Proc Natl Acad Sci. 2015;112:4489-94. doi:10.1073/pnas.1419228112.

6. Boillee S, Yamanaka K, Lobsiger CS, Copeland NG, Jenkins NA, Kassiotis G, et al. Onset and progression in inherited ALS determined by motor neurons and microglia. Science. 2006;312:1389-92. doi:10.1126/science.1123511.

7. Boland B, Kumar A, Lee S, Platt FM, Wegiel J, Yu WH, et al. Autophagy induction and autophagosome clearance in neurons: relationship to autophagic pathology in Alzheimer's disease. J Neurosci. 2008;28:6926-37. doi:10.1523/jneurosci.0800-08.2008.

8. Bosco DA, Morfini G, Karabacak NM, Song Y, Gros-Louis F, Pasinelli P, et al. Wild-type and mutant SOD1 share an aberrant conformation and a common pathogenic pathway in ALS. Nat Neurosci. 2010;13:1396-403. doi:10.1038/nn.2660.

9. Boya P, Kroemer G. Lysosomal membrane permeabilization in cell death. Oncogene. 2008;27:6434-51. doi:10.1038/onc.2008.310.

10. Brooks BR, Miller RG, Swash M, Munsat TL. El Escorial revisited: revised criteria for the diagnosis of amyotrophic lateral sclerosis. Amyotroph Lateral Scler Other Motor Neuron Disord. 2000;1:293-9. doi:10.1080/146608200300079536.

11. Burke R, Marks W. Some Approaches to Quantitative Dendritic Morphology. In: Ascoli G, editor. Computational Neuroanatomy. City: Humana Press; 2002. p. $27-48$.

12. Choi AM, Ryter SW, Levine B. Autophagy in human health and disease. N Engl J Med. 2013;368:651-62. doi:10.1056/NEJMra1205406.

13. Ciechomska IA, Goemans GC, Skepper JN, Tolkovsky AM. BCl-2 complexed with Beclin-1 maintains full anti-apoptotic function. Oncogene. 2009;28: 2128-41. doi:10.1038/onc.2009.60.

14. Cirulli ET, Lasseigne BN, Petrovski S, Sapp PC, Dion PA, Leblond CS, et al. Exome sequencing in amyotrophic lateral sclerosis identifies risk genes and pathways. Science. 2015;347:1436-41. doi:10.1126/science.aaa3650.
15. Cooper-Knock J, Kirby J, Highley R, Shaw PJ. The spectrum of C9orf72 mediated neurodegeneration and amyotrophic lateral sclerosis. Neurotherapeutics. 2015;12:326-39. doi:10.1007/s13311-015-0342-1.

16. Forsberg K, Andersen PM, Marklund SL, Brannstrom T. Glial nuclear aggregates of superoxide dismutase-1 are regularly present in patients with amyotrophic lateral sclerosis. Acta Neuropathol. 2011;121:623-34. doi:10.1007/s00401-011-0805-3.

17. Forsberg K, Jonsson PA, Andersen PM, Bergemalm D, Graffmo KS, Hultdin $\mathrm{M}$, et al. Novel antibodies reveal inclusions containing nonnative SOD1 in sporadic ALS patients. PLoS One. 2010;5:e11552. doi:10.1371/journal.pone.0011552.

18. Freischmidt A, Wieland T, Richter B, Ruf W, Schaeffer V, Muller K, et al. Haploinsufficiency of TBK1 causes familial ALS and fronto-temporal dementia. Nat Neurosci. 2015;18:631-6. doi:10.1038/nn.4000.

19. Friese A, Kaltschmidt JA, Ladle DR, Sigrist M, Jessell TM, Arber S. Gamma and alpha motor neurons distinguished by expression of transcription factor Err3. Proc Natl Acad Sci U S A. 2009;106:13588-93. doi:10.1073/pnas.0906809106.

20. Gould TW, Buss RR, Vinsant S, Prevette D, Sun W, Knudson CM, et al. Complete dissociation of motor neuron death from motor dysfunction by Bax deletion in a mouse model of ALS. J Neurosci. 2006;26:8774-86. doi:10.1523/jneurosci.2315-06.2006.

21. Grad LI, Yerbury JJ, Turner BJ, Guest WC, Pokrishevsky E, O'Neill MA, et al. Intercellular propagated misfolding of wild-type Cu/Zn superoxide dismutase occurs via exosome-dependent and -independent mechanisms. Proc Natl Acad Sci USA. 2014;111:3620-5. doi:10.1073/pnas.1312245111.

22. Graffmo KS, Forsberg K, Bergh J, Birve A, Zetterstrom P, Andersen PM, et al. Expression of wild-type human superoxide dismutase-1 in mice causes amyotrophic lateral sclerosis. Hum Mol Genet. 2013;22:51-60. doi:10.1093/hmg/dds399.

23. Gurney ME, Pu H, Chiu AY, Dal Canto MC, Polchow CY, Alexander DD, et al. Motor neuron degeneration in mice that express a human $\mathrm{Cu}, \mathrm{Zn}$ superoxide dismutase mutation. Science. 1994;264:1772-5. doi:10.1126/science.8209258.

24. Hardy J, Rogaeva E. Motor neuron disease and frontotemporal dementia: sometimes related, sometimes not. Exp Neurol. 2014;262pb:75-83. doi:10. 1016/j.expneurol.2013.11.006

25. Hetz C, Thielen P, Matus S, Nassif M, Court F, Kiffin R, et al. XBP-1 deficiency in the nervous system protects against amyotrophic lateral sclerosis by increasing autophagy. Genes Dev. 2009;23:2294-306. doi:10.1101/gad.1830709.

26. Ilieva H, Polymenidou M, Cleveland DW. Non-cell autonomous toxicity in neurodegenerative disorders: ALS and beyond. J Cell Biol. 2009;187:761-72. doi:10.1083/jcb.200908164.

27. Jonsson PA, Bergemalm D, Andersen PM, Gredal O, Brannstrom T, Marklund SL. Inclusions of amyotrophic lateral sclerosis-linked superoxide dismutase in ventral horns, liver, and kidney. Ann Neurol. 2008;63:671-5. doi:10.1002/ana.21356.

28. Jonsson PA, Ernhill K, Andersen PM, Bergemalm D, Brannstrom T, Gredal O, et al. Minute quantities of misfolded mutant superoxide dismutase-1 cause amyotrophic lateral sclerosis. Brain. 2004;127:73-88. doi:10.1093/brain/awh005

29. Jonsson PA, Graffmo KS, Andersen PM, Brannstrom T, Lindberg M, Oliveberg M, et al. Disulphide-reduced superoxide dismutase-1 in CNS of transgenic amyotrophic lateral sclerosis models. Brain. 2006;129:451-64. doi:10.1093/brain/awh704.

30. Jonsson PA, Graffmo KS, Andersen PM, Marklund SL, Brannstrom T. Superoxide dismutase in amyotrophic lateral sclerosis patients homozygous for the D90A mutation. Neurobiol Dis. 2009:36:421-4. doi:10.1016/j.nbd.2009.08.006.

31. Kato S, Takikawa M, Nakashima K, Hirano A, Cleveland DW, Kusaka H, et al. New consensus research on neuropathological aspects of familial amyotrophic lateral sclerosis with superoxide dismutase 1 (SOD1) gene mutations: inclusions containing SOD1 in neurons and astrocytes. Amyotroph Lateral Scler Other Motor Neuron Disord. 2000;1:163-84. doi:10.1080/14660820050515160

32. Komatsu M, Waguri S, Koike M, Sou YS, Ueno T, Hara T, et al. Homeostatic levels of p62 control cytoplasmic inclusion body formation in autophagy-deficient mice. Cell. 2007;131:1149-63. doi:10.1016/j.cell.2007.10.035.

33. Korolchuk VI, Mansilla A, Menzies FM, Rubinsztein DC. Autophagy inhibition compromises degradation of ubiquitin-proteasome pathway substrates. Mol Cell. 2009;33:517-27. doi:10.1016/j.molcel.2009.01.021.

34. Lang L, Kurnik M, Danielsson J, Oliveberg M. Fibrillation precursor of superoxide dismutase 1 revealed by gradual tuning of the protein-folding equilibrium. Proc Natl Acad Sci USA. 2012;109:17868-73. doi:10.1073/pnas.1201795109.

35. Lang L, Zetterstrom P, Brannstrom T, Marklund SL, Danielsson J, Oliveberg M. SOD1 aggregation in ALS mice shows simplistic test tube behavior. Proc Natl Acad Sci USA. 2015;112:9878-83. doi:10.1073/pnas.1503328112. 
36. Lucin KM, O'Brien CE, Bieri G, Czirr E, Mosher Kl, Abbey RJ, et al. Microglial beclin 1 regulates retromer trafficking and phagocytosis and is impaired in Alzheimer's disease. Neuron. 2013;79:873-86. doi:10.1016/j.neuron.2013.06.046.

37. Matsunaga K, Saitoh T, Tabata K, Omori H, Satoh T, Kurotori N, et al. Two Beclin 1-binding proteins, Atg14L and Rubicon, reciprocally regulate autophagy at different stages. Nat Cell Biol. 2009;11:385-96. doi:10.1038/ncb1846.

38. McKnight NC, Zhong Y, Wold MS, Gong S, Phillips GR, Dou Z, et al. Beclin 1 is required for neuron viability and regulates endosome pathways via the UVRAG-VPS34 complex. PLoS Genet. 2014;10:e1004626. doi:10.1371/journal. pgen. 1004626

39. Nassif M, Valenzuela V, Rojas-Rivera D, Vidal R, Matus S, Castillo K, et al. Pathogenic role of BECN1/Beclin 1 in the development of amyotrophic lateral sclerosis. Autophagy. 2014;10:1256-71. doi:10.4161/auto.28784.

40. Pedro JM, Wei Y, Sica V, Maiuri MC, Zou Z, Kroemer G, et al. BAX and BAK1 are dispensable for ABT-737-induced dissociation of the BCL2-BECN1 complex and autophagy. Autophagy. 2015;1 1:452-9. doi:10.1080/15548627.2015.1017191.

41. Pickford F, Masliah E, Britschgi M, Lucin K, Narasimhan R, Jaeger PA, et al. The autophagy-related protein beclin 1 shows reduced expression in early Alzheimer disease and regulates amyloid beta accumulation in mice. J Clin Invest. 2008;118:2190-9. doi:10.1172/jici33585.

42. Price JC, Guan S, Burlingame A, Prusiner SB, Ghaemmaghami S. Analysis of proteome dynamics in the mouse brain. Proc Natl Acad Sci USA. 2010;107: 14508-13. doi:10.1073/pnas.1006551107.

43. Puls I, Jonnakuty C, LaMonte BH, Holzbaur EL, Tokito M, Mann E, et al. Mutant dynactin in motor neuron disease. Nat Genet. 2003;33:455-6. doi:10.1038/ng1123.

44. Qu X, Yu J, Bhagat G, Furuya N, Hibshoosh H, Troxel A, et al. Promotion of tumorigenesis by heterozygous disruption of the beclin 1 autophagy gene. J Clin Invest. 2003;112:1809-20. doi:10.1172/jci20039.

45. Ravits JM, La Spada AR. ALS motor phenotype heterogeneity, focality, and spread: deconstructing motor neuron degeneration. Neurology. 2009;73: 805-11. doi:10.1212/WNL.0b013e3181b6bbbd.

46. Shaid S, Brandts $\mathrm{CH}$, Serve H, Dikic I. Ubiquitination and selective autophagy. Cell Death Differ. 2013;20:21-30. doi:10.1038/cdd.2012.72.

47. Sinha S, Levine B. The autophagy effector Beclin 1: a novel BH3-only protein. Oncogene. 2008;27 Suppl 1:S137-148. doi:10.1038/onc.2009.51.

48. Stewart HG, Mackenzie IR, Eisen A, Brannstrom T, Marklund SL, Andersen PM. Clinicopathological phenotype of ALS with a novel G72C SOD1 gene mutation mimicking a myopathy. Muscle Nerve. 2006;33:701-6. doi:10.1002/mus.20495.

49. Strucksberg KH, Tangavelou K, Schroder R, Clemen CS. Proteasomal activity in skeletal muscle: a matter of assay design, muscle type, and age. Anal Biochem. 2010;399:225-9. doi:10.1016/j.ab.2009.12.026.

50. Tan JM, Wong ES, Kirkpatrick DS, Pletnikova O, Ko HS, Tay SP, et al. Lysine 63-linked ubiquitination promotes the formation and autophagic clearance of protein inclusions associated with neurodegenerative diseases. Hum Mol Genet. 2008;17:431-9. doi:10.1093/hmg/ddm320.

51. Tokuda E, Okawa E, Watanabe S, Ono S, Marklund SL. Dysregulation of intracellular copper homeostasis is common to transgenic mice expressing human mutant superoxide dismutase-1 s regardless of their copper-binding abilities. Neurobiol Dis. 2013;54:308-19. doi:10.1016/j.nbd.2013.01.001.

52. Vidal RL, Matus S, Bargsted L, Hetz C. Targeting autophagy in neurodegenerative diseases. Trends Pharmacol Sci. 2014;35:583-91. doi:10. 1016/j.tips.2014.09.002.

53. Wroe R, Wai-Ling Butler A, Andersen PM, Powell JF, Al-Chalabi A. ALSOD: the amyotrophic lateral sclerosis online database. Amyotroph Lateral Scler. 2008;9:249-50. doi:10.1080/17482960802146106.

54. Zetterstrom P, Graffmo KS, Andersen PM, Brannstrom T, Marklund SL. Composition of soluble misfolded superoxide dismutase-1 in murine models of amyotrophic lateral sclerosis. Neuromolecular Med. 2013;15:147-58 doi:10.1007/s12017-012-8204-z.

55. Zetterstrom P, Stewart HG, Bergemalm D, Jonsson PA, Graffmo KS, Andersen PM, et al. Soluble misfolded subfractions of mutant superoxide dismutase-1 $\mathrm{s}$ are enriched in spinal cords throughout life in murine ALS models. Proc Natl Acad Sci U S A. 2007;104:14157-62. doi:10.1073/pnas. 0700477104

56. Zhang X, Li L, Chen S, Yang D, Wang Y, Zhang $X$, et al. Rapamycin treatment augments motor neuron degeneration in SOD1(G93A) mouse model of amyotrophic lateral sclerosis. Autophagy. 2011;7:412-25. doi:10.4161/auto.7.4.14541.

\section{Submit your next manuscript to BioMed Central and we will help you at every step:}

- We accept pre-submission inquiries

- Our selector tool helps you to find the most relevant journal

- We provide round the clock customer support

- Convenient online submission

- Thorough peer review

- Inclusion in PubMed and all major indexing services

- Maximum visibility for your research

Submit your manuscript at www.biomedcentral.com/submit

) Biomed Central 